University of Louisville

ThinkIR: The University of Louisville's Institutional Repository

Faculty Scholarship

$9-2005$

\title{
Influence of general self-efficacy on the effects of a school-based universal primary prevention program of depressive symptoms in adolescents : a randomized and controlled follow-up study.
}

\author{
Patrick Pössel \\ University of Louisville \\ Christiane Baldus \\ University of Tuebingen \\ Andrea B. Horn \\ University of Tuebingen \\ Gunter Groen \\ University of Bremen

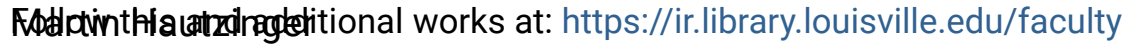 \\ iversity of Tuebingen \\ Psychology Commons
}

\section{Original Publication Information}

This is the peer reviewed version of the following article:

Pössel, Patrick, Christiane Baldus, Andrea B. Horn, Gunter Groen and Martin Hautzinger. "Influence of General Self-efficacy on the Effects of a School-based Unviersal Primary Prevention Program of Depressive Symptoms in Adolescents: A Randomized and Controlled Follow-up Study." 2005. Journal of Child Psychology and Psychiatry 46(9): 982-994.

which has been published in final form at https://doi.org/10.1111/j.1469-7610.2004.00395.x This article may be used for non-commercial purposes in accordance with Wiley Terms and Conditions for Self-Archiving.

This Article is brought to you for free and open access by ThinkIR: The University of Louisville's Institutional Repository. It has been accepted for inclusion in Faculty Scholarship by an authorized administrator of ThinkIR: The University of Louisville's Institutional Repository. For more information, please contact thinkir@louisville.edu. 
Running head: SELF-EFFICACY IN PREVENTION OF DEPRESSION

Influence of general self-efficacy on the effects of a school-based universal primary prevention program of depressive symptoms in adolescents: A randomized and controlled follow-up study

Patrick Pössel, Christiane Baldus, Andrea B. Horn, University of Tuebingen at Tuebingen, Germany

Gunter Groen and

University of Bremen at Bremen, Germany

Martin Hautzinger

University of Tuebingen at Tuebingen, Germany 


\begin{abstract}
Background: Depressive disorders in adolescents are a widespread and increasing problem. Prevention seems a promising and feasible approach.

Methods: We designed a cognitive-behavioral school-based universal primary prevention program and followed 347 eighth-grade students participating in a randomized controlled trial for three months.

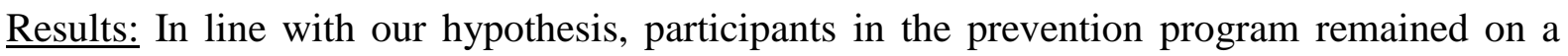
low level of depressive symptoms, having strong social networks. The control group showed increasing depressive symptoms and a reduced social network. Contrary to our expectations students low in self-efficacy benefited more from the program than high self efficient students. Social network did not mediate the relationship between participation in the prevention program and changes in depressive symptoms.

Conclusions: Our results show that the prevention program had favorable effects. Further research is needed to explore the impact of self-efficacy on the effects of prevention programs.
\end{abstract}

Keywords: depression, universal prevention, adolescence, self-efficacy, cognitive-behavioral intervention 
Influence of general self-efficacy on the effects of a school-based universal primary prevention program of depressive symptoms in adolescents

Depressive disorders in adolescents are a widespread problem. A multitude of studies report lifetime prevalence of $15-20 \%$ to majority (Birmaher, Ryan, Williamson, Brent, Kaufman, Dahl, Perel, \& Nelson, 1996). Depressive symptoms at young age increase the probability of depression (e.g., Weissman, et al., 1999) and other psychopathologies later in life (Birmaher et al., 1996). Depressive disorders also come along with psychosocial impairments such as considerably increased difficulty in school (e.g., Birmaher et al., 1996): lower mean grades, impaired relationships to teachers, siblings, and friends (Vernberg, 1990). The consequences of depressive disorders that develop at adolescence seem to persist until years after adolescence (Harrington, Fudge, Rutter, Pickles, \& Hill, 1990).

Important risk factors for developing depressive symptoms are external influences such as critical life events and daily hassles. Negative life events are defined as rare but profound events, whereas daily hassles are common, everyday irritations and frustrating incidents (Dumont \& Provost, 1999). Comparing negative life events and daily hassles, recent studies show that the two concepts explain different shares of variance (e.g., Sheeber, Hops, \& Davis, 2001). Research on functional thoughts (Lightsey, 1994), which are defined as realistic and helpful thoughts (Pössel, Horn, Seemann, \& Hautzinger, 2004), and on social support (Bennett \& Bates, 1995) found that both are protective factors for the development of depression caused by daily hassles and negative life events.

So-called "subsyndromal depression" has been found to be another serious risk factor for future diagnosable episodes of major depression in youth or later life (Compas, Ey, \& Grant, 1993; Lewinsohn, Solomon, Seeley, \& Zeiss, 2000). Subsyndromal depression refers to the occurrence of one to four out of eight DSM-IV symptoms for the diagnosis of major depression (Brent, Birmaher, Kolko, Baugher, \& Bridge, 2001). 


\section{Depression: prevention and therapy}

In prevention and therapy of major depression in children and adolescents, cognitivebehavioral therapy has proven most effective (Clarke, Rohde, Lewinsohn, Hops, \& Seeley, 1999). Also, studies with high-risk groups (e.g., subsyndromal depressive disorder, Clarke, Hornbrook, Lynch, Polen, Gale, Beardslee, O’Connor, \& Seeley, 2001) yielded favorable results for cognitive-behavioral treatment. In their meta analysis, Durlak and Wells (1997) found effect sizes twice as high for behavioral and cognitive-behavioral programs than for other prevention programs $(\mathrm{ES}=0.49$ and $\mathrm{ES}=0.25$, respectively). Despite these favourable outcomes, two issues remain: First, interpersonal psychotherapy (IPT; Moreau, Mufson, Weissman, \& Kleman, 1991) is used successfully for adolescents, but has not yet been used for prevention. Thus, we do not know its effect sizes in prevention. Second, program effectiveness differs depending on its use as prevention or as therapy. Clarke et al. (2001) found that the "Adolescent Coping with Depression Course" is a well-evaluated intervention and highly effective for adolescents with subsyndromal depression and a parent with depression. However, the same intervention did not prove effective for adolescents with major depression.

Clarke, Hawkins, Murphy, and Sheeber (1993) showed that merely enlarging children's knowledge about psycho-social factors does not affect prevalence of major depression. Instead, they recommend focusing on additional skill practice. Studies on selective prevention programs generally face recruitment difficulties as well as high drop-out rates (Clarke et al., 1993; Gillham, Reivich, Jaycox, \& Seligman, 1995). Shochet, Dadds, Holland, Whitefield, Harnett, and Osgarby (2001) argue that peer acceptance is of major importance for adolescents. However, a selective prevention program targets individuals whose risk of developing a major depression is significantly higher than average, and thus might stigmatise the individual participant. Therefore, Shochet et al. (2001) advocate universally applied 
programs which target the population of complete school years, including all students independent from the individual's risk for major depression. They recommend establishing the program within the context of regular classes.

Evaluations of presently established universal prevention programs for depression in adolescence have shown inconsistent effects: Clarke et al. (1993) failed to show positive effects on self-reported depressive symptoms with their program. Shochet et al. (2001), on the other hand, reported significant positive effects on students' depressive symptoms within the post-intervention period as well as at a 10-month follow-up. However, Shochet et al. (2001) did not control for inter-correlations between students of the same class (Hopkins, 1982). This might lead to misinterpretations of the empirical results due to the reciprocal influence and alignment between the individual and his group and the resulting enlargement of differences between groups (Goldstein, 1995). Using a mixed-model repeated measures analysis of variance addresses this issue. In addition, the authors failed to adequately adjust alpha in their post hoc testing, which presumably leads to overestimation of effects.

Because the majority of participants in universal primary prevention programs will not develop a major depression, the main goal of the program is the prevention of the increase of depressive symptoms compared to a non-treatment control group (distal objective). In addition to the analysis of depressive symptoms, we studied risk factors for the development of depressive disorders (proximal objectives), such as automatic thoughts (Beck, Rush, Shaw, \& Emery, 1979), and social resources like social networks and social support (Barrera \& Garrison-Jones, 1992). Both aspects are central to the program and expected to reduce or prevent the development of depressive symptoms.

Of great relevance for the effectiveness of the program is the participating students' age. Due to the fact that the prevalence of depression increases in adolescence, Compas, Connor, and Wadsworth (1997) suggest conducting prevention programs in early adolescence, 
preceding the beginning of increasing incidence as closely to the rise of depression rates as possible. Relevant studies claim an increase in depression rate at the age of 13 (eighth grade) or later (Nolen-Hoeksema \& Girgus, 1994). Thus, it seems the right time to apply a universal primary prevention program to prevent the incidences of depression that are expected to happen at this age.

\section{Self-efficacy}

Central to social-cognitive theory is the concept of self-efficacy, introduced by Bandura (1977). First developed to establish a theoretical framework for explaining and predicting psychological change, self-efficacy was defined as the “...conviction, that one can successfully execute the behavior required to produce the outcomes." (Bandura, 1977, p. 193). Self-efficacy plays a major role when linking cognitions, motivation, and actual behavior, because self-efficacy is regarded as having a strong impact on the choice of activities, the choice of environments, as well as the amount of energy and persistence one is willing to invest in a certain behavior. Although the original concept of self-efficacy was one of rather high specificity for different activities, Bandura states that self-efficacy expectations have a strong tendency to generalize: The belief of being able to perform a certain activity successfully in one domain easily affects the same expectation in another domain (Bandura, 1977). People low in self-efficacy are more likely to perceive themselves as incompetent and deficient, to overestimate failure, and thus to develop behavioral deficits and depressive symptoms (Bandura, 1977). From this starting position, Schwarzer introduced general selfefficacy as a rather stable attribute reflecting the personal conviction of being able to cope successfully with difficult situations (Schwarzer, 1994). General self-efficacy as Schwarzer understands it is a personality trait that refers to a person's expectation about the whole spectrum of activities that this person is able to perform successfully. General self-efficacy, too, is expected to play a central role in motivation and thus is a prerequisite for initiating 
action. Both self-efficacy and general self-efficacy are widely used concepts in various fields of psychological research.

As proposed by Coie and colleagues (Coie et al., 1993), the evaluation of differential effects of prevention programs on different groups may be important in order to learn more about the mechanisms and limitations of such efforts. Thus self-efficacy and general selfefficacy may play a key role in training and prevention programs: Even if people understood to what extend certain techniques (e.g., cognitive restructuring) help to shape a certain outcome (e.g., mood), nothing is yet said about whether they believe themselves able to perform that technique and hence will apply it later on. However, although self-efficacy proves to have to strongly influence motivation and behavior, only few studies have focused on the influence of self-efficacy on the effectiveness of training and prevention programs. Colquitt, LePine, and Noe (2000) report in a meta-analysis that self-efficacy measured prior to training sessions correlates with learning motivation $(r=.42)$, the acquisition of skills $(r=$ $.32)$, and the transfer of skills into daily routines $(r=.47)$. With regard to an abuse prevention program for children, Dumont, Hébert, and Lavoie (1999) found that children high on self-efficacy benefited more from the program than their peers low on self-efficacy. This is in line with results presented by Klauer (2000), who found that people high on selfefficacy were better able to accept help and to make use of this help.

\section{Hypotheses}

We expect the cognitive-behavioral primary prevention program to reduce risk factors for depression (mediating variables) during adolescence and thus prevent the increase of depressive symptoms (distal objective). We suggest that our program affects automatic thoughts (Beck et al., 1979) and improves social skills to establish and cultivate friendships and to use social resources (e. g., social network and social support, proximal objective). We also expect differential effects for subgroups according to magnitude of general self-efficacy: 
Students with high general self-efficacy should benefit particularly strongly from the prevention program by showing less dysfunctional (i.e., unrealistic, self devaluating) automatic thoughts and increased care and use of social support (network size and frequency of use of social network). We therefore expect students with high general self-efficacy to enlarge and extent their use of social networks, because they to be more motivated to learn new skills and transfer them into their daily life.

\section{Method}

\section{Participants}

First, letters were sent to the principals of all middle schools in the area of Tuebingen (Germany), asking for their school's participation in this project. Next, consent forms were sent to the parents of the eighth-graders at the six participating schools. Classes within each school were randomly assigned either to the training or to the control group by tossing a coin. We tried to recruit both the training and the control group in each school so that one class was randomly assigned to one group and the other class was assigned to the other group automatically; however, there was one school with only one class, which we deliberately assigned to the training group. In another school with three classes, we randomly selected two classes as training groups, the third class was automatically assigned to the control condition. Separation of each school's classes with regard to certain conditions was necessary in order to increase statistical power with constant sample sizes: variances between schools are often four times the size of variances between classes of the same school (Brown \& Liao, 1999). Therefore, within the schools, classes were assigned to either training or control group. Also, this way there was no need to consider the school as a group factor in the statistical analysis.

The sample of 347 eighth-grade students from six different schools was randomly assigned to the training group (113 boys and 87 girls) of seven classes, with a mean age of 
13.82 (SD .71), or to the control group (68 boys, 79 girls) of five classes, with a mean age of 14.18 (SD .78). For five students (5/347), no parental consent was given. Thus, 342 students were class-wise assigned to training or control group. A total of 39 students (39/347) did not participate in all the assessments, due to changing schools. Dropout was higher in the training group $(n=28)$ than in the control group $\left(n=11 ; \chi^{2}(1)=8.16, p<.001\right)$, which is due to the circumstance that administration of the prevention program was relocated to less central lessons for one class. As a consequence, 15 boys and nine girls quit the training ahead of schedule. Analysis shows that drop-outs before the second assessment point are older than the other adolescents $(\underline{t}(1)=4.03, \underline{p}<.05)$ and more likely male than female $\left(\chi^{2}\right.$ $(1)=6.21, \underline{p}<.05)$. No significant effect of severity of depression was found for drop-outs ( $\underline{t}$ $(1)=.12, p=.734)$. Thus, 303 students $(303 / 347)$ of the original sample provided utilizable data. Nine students of the training group and 15 students of the control group (in total 24/303) scored in the clinical range. Following Shochet, Dadds, Holland, Whitefield, Harnett, and Osgarby (2001), we let these youths continue with the universal program, but excluded them from the data analysis. It is very likely that they qualified for a diagnosis of major depression. In this case, prevention is not the training of choice; systematic intervention for major depression would have been necessary. Finally, we included data of 163 students of the training group and 116 students of the control group in our analyses (Figure 1).

\section{Measures}

\section{Distal Objective}

Radloff (1977) developed the Center for Epidemiological Studies - Depression Scale $(C E S-D)$ as a quickly administered, economic screening instrument able to measure current depressive symptoms based on self-reports. The CES-D has been repeatedly applied to youths (e.g., Roberts, Andrews, Lewinsohn, \& Hops, 1990). The CES-D consists of 20 
items, e.g., "During the past week, there were things that upset me that usually do not upset me." On a four-point scale ranging from 0 to 3, frequency of symptoms is rated, with higher numbers indicating higher frequency of occurrence. Item values are summed, creating a range from 0 to 60. In our sample, internal consistency was $\alpha=.83$ (Cronbach's Alpha).

\section{Proximal objectives}

The Automatic Thought Questionnaire (ATQ; Hollon \& Kendall, 1980) measures dysfunctional thoughts. Originally developed for adults, the ATQ has also been successfully used with adolescents 12 years and older (e.g., Garber, Weiss, \& Shanley, 1993). For adolescents as well as for adults, the ATQ values vary with regard to severity of depression, not with regard to age (Graber et al., 1993). The ATQ consists of 30 items (e. g., "Nobody understands me!') ranging from 1 to 5 , with 5 indicating the most frequent occurrence of dysfunctional thoughts. In our sample, the total sum score of all item values ranged from 30 to 150 , with an internal consistency (Cronbach's Alpha) of $\alpha=.96$.

The Questionnaire of Social Support (FESU; Bliesener, 1991) is a self-report measure for various aspects of social support. Each question addresses a certain problem and asks about persons who help and support the adolescent (network size, FESU-N), and how often the adolescent asks assistance of each of these persons (frequency, FESU-F). For example, one of the items asked, "Who do you talk to if you feel dejected?" The FESU comprises six items. The number of persons that can be named in each item is not limited (network size). Students rate frequency between 1 and 5 for each named person, with higher values indicating higher frequency. Mean values including all named persons are calculated for each item. Each of the two indices, network size and frequency, is averaged over all six items. Internal consistency in our sample was $\alpha=.83$ for network size and $\alpha=.81$ for frequency (Cronbach’s Alpha). 


\section{Moderating Variables}

The General Self-Efficacy Scale (GSE) by Jerusalem and Schwarzer (1986) refers to the concept of general self-efficacy by Schwarzer (1994). For example, an item is: "If a problem occurs, I am able to deal with it by myself." GSE consists of 10 questions, each to be answered using a four-point scale with 1 indicating "not true", 4 indicating "very true". After completion of the form, subjects' values are added up. Sums range from 10 to 40, with high sums indicating high general self-efficacy of subjects. Internal consistency in our sample was $\alpha=.87$ (Cronbach's Alpha).

The Bremen Youth's Event List (BJL) by Essau, Karpinski, Petermann, and Conradt (1998) is a checklist of life events that allows retrospective measurement of positive and negative life events of youths or youths' significant others. Items such as "Has something important happened in your family during the last three months?" are grouped according to eight life areas: school/apprenticeship; parents/family; social contacts/leisure time activities; romantic relationships; events of death; place of residence; law; health/medical condition. We restricted the period of assessment to three months. The score was added up over all areas of life. Sums ranged from 0 to 55, with high sums indicating a high number of life events. Internal consistency in our study was quite low with a Cronbach's Alpha of .52. According to Essau et al. (1998), this is due to the varying nature of the events we asked for.

The Daily Hassles and Daily Uplifts Questionnaire (HASSUP) by Quast, Jerusalem, and Faulhaber (1986) is a self-assessment instrument of negative events (daily hassles) and positive events (daily uplifts) in adolescents' everyday lives. HASSUP consists of 27 items for daily hassles (e.g., "I had a row with my best friend.") and 33 items for daily uplifts (e.g., "One of my teachers praised my work."). For each event, subjects choose "true" if the event has happened and "not true" if it has not happened during the previous four weeks. Item values are added up for daily hassles and daily uplifts separately (range 0-27 and 0-33, 
respectively). In our sample, internal consistency (Cronbach's Alpha) was $\alpha=.78$ for daily hassles and $\alpha=.77$ for daily uplifts.

The Evaluation Questionnaire by Kröger, Kutza, Walden, and Reese (1998) measures adolescents' acceptance of the prevention program. At the end of every session, students used the questionnaire to rate how boring, how exciting, and how much fun the session was. In addition, students stated a) whether they had learned anything in the session that is of use in their everyday life; b) whether they had thought about themselves and their behavior; and c) how much they liked the trainers. Items are rated on a five-point scale (A-E), with a lower score indicating higher agreement.

The Universal Primary Prevention: Training the Ease of Handling Social Aspects in Everyday Life - (LISA)

Our manualised school-based universal primary prevention program is based on the social information processing model of social competence as described by Dodge (1993). During the process of encoding, selective perception filters relevant aspects of the stimulus, which are then stored in short term memory. Depressed children and adolescents process information with a bias toward those aspects that are consistent with their negative selfschema (Beck et al., 1979). In general, stimuli are stored in memory primarily according to their significance for the individual ("mental representation"). Significance depends on attribution style (Abramson, Alloy, \& Metalsky, 1989), on the cognitive triad of negative views on the self, the world, and the future, and on cognitive errors (Beck et al., 1979). By "response accessing", one or more possible reactions, emotional or behavioral, are initiated. Each mental representation relates to a series of possible reactions, such as verbalization, physical activity, endocrine secretion, arousal of the autonomous systems, and affect. In this stage of information processing, the individual evaluates the prepared reactions on the basis of morale, acceptability, and/or anticipated consequences ("response evaluation selection"). 
If one of the prepared reactions fulfils evaluation criteria, it can be initiated ("enactment"). In line with Dodge (1993), behaviors can be verbalizations, motor activity, autonomous activity, and others.

Methods used are taken from cognitive-behavioral therapy. Based on Dodge's (1993) model, our prevention program targets on cognitive and social aspects, which can be further differentiate as follows: a) illustrating the relationship between cognition, emotion, and behavior (3 hours); b) exploring and changing dysfunctional cognitions (4.5 hours); c) assertiveness training ( 3 hours); d) training of social competence (3 hours). Each program part is designed to address one stage of information processing according to Dodge (1993) and to improve knowledge and skills. The cognitive part of the program ("illustrating the relationship between cognition, emotion, and behavior" and "exploring and changing dysfunctional cognitions") refers to Dodge's (1993) stage of "mental representation". It is designed to decrease underlying dysfunctional cognitions and to increase functional cognitions. Second, the cognitive part also works at the stage of "response accessing", because the development of functional cognitions makes adolescents' emotional reactions more appropriate (Beck et al., 1979). Thus, adolescents are expected to show less sadness, less anger, and more pleasure even with failure experiences in school and social rejection. Third, the cognitive aspects of the program apply to the stage of "response evaluation and selection" by changing evaluation of behavior consequences. Students' self-efficacy in social interactions increases as they develop functional cognitions. They frequent social interactions and come to see them as a possible alternative against withdrawal.

The social part of the program, including the assertiveness training and the training of social competence, refers to the stages "response accessing", "response evaluation and selection", and "enactment". "Response accessing" follows the rules of associative networks. Therefore, the training of new or unfamiliar functional behaviors in role plays leads to 
increased recognition about their possible value as alternative behaviors. Positive reinforcement during the training encourages students' positive evaluation of their behaviors beyond the program. Such effects can be observed on the stage of "response evaluation and selection". We also expect more functional behavior on the stage of "enactment". Increasingly adaptive social behavior enables students to develop their individual social network, to enlarge it, and to improve using it.

Acceptance ratings show that more than $2 / 3$ of the students felt the two main components of LISA to be fun, exciting, and/or not boring. 189/294 of the students graded applicability of the cognitive component with B ("good") or better. 179/294 thought the social component to be good or very good. We conclude that LISA was well accepted by the adolescents, and that content and skills were conveyed in a suitable fashion (Pössel, Horn, \& Hautzinger, 2003).

\section{Design and Procedure of LISA}

In order to test the effects of our program, we used a prospective design comprising a training group and a control group at three being evaluated at three points of time (preassessment, post-assessment, 3-month follow-up).

The prevention program was administered once a week over a 10 -week period in the context of regular school lessons. One meeting took two lessons, i.e. a total of 1.5 hours. During this time the control classes attended their usual lessons. Training classes were divided into two groups according to sex, because a pilot study has shown more cooperation between the students when the sexes were separated. Thus, intervention groups varied in size from 8 to 24 students.

Each group was coached by one trainer and one co-trainer. Thus, each school class required a total of four trainers, who were either psychologists (M.A. level) or graduate students experienced in working with adolescents. Supervision was provided for all trainers 
with video recordings of the training sessions and a 1.5 -hour weekly meeting with the first author. We also used the recordings to ensure that trainers adhered to the manual.

No teacher was allowed to participate or remain in the classroom during sessions because students are likely to be socialized with the teacher's academic role, which is associated with achievement orientation and the regular normative school setting. In contrast, the prevention program LISA requires an atmosphere that allows making mistakes and promotes practice, especially when it comes to the acquisition of social skills (Hurrelmann \& Settertobulte, 2000).

Adolescents, parents, and teachers of training and control group were informed about the program's objectives: to strengthen certain abilities of the students and to facilitate their coping with puberty-specific strains (proximal objective). We explained that having a control group is essential in order to study the program's effectiveness. The study was approved by the ethical committee of the German Psychological Association under the title "Universal Prevention of Depression among Adolescents". The approved protocol states that participants were not to be told the main goal of the study (prevention of an increase of depressive symptoms during adolescents) to prevent any stigmatization of the participating youths.

Data Analysis

Interactions between students of the same class or school lead to inter-correlation of variables and create a general methodological problem in school-based studies (Hopkins, 1982). Disregarding group variables may cause misinterpretations of results because natural groups, such as classes, cause reciprocal influence between individual and group, and thus lead to enhanced group-specific differences between individuals (Goldstein, 1995). Therefore, data were analyzed with a mixed-model repeated measures analysis of variance, 
with class nested within condition, and students nested within class and condition ${ }^{1}$. School does not have to be considered as a grouping variable because in each school both conditions were administered.

Our dependent variables were the depression scores of the CES-D (distal objective) as well as automatic thoughts (ATQ; proximal objective) and social support (FESU-N \& FESUF; proximal objective). The independent variables were time (pre-assessment vs. postassessment vs. 3-month follow-up); condition (training group vs. control group); and initial general self-efficacy (low general self-efficacy vs. high general self-efficacy). In order to differentiate between participants with high and low self-efficacy, we performed a median split (median $=27$ ) which mirrored the bipolar distribution of the GSE. We formulated hypotheses only for the condition $\mathrm{x}$ time interaction and the condition $\mathrm{x}$ time $\mathrm{x}$ self-efficacy interaction. Therefore, we calculated a posteriori tests only if these interactions were significant.

According to a meta-analysis by Llopis (2002), universal preventions programs for children and adolescents show effect sizes of $d=.31$. We did an a priori power calculation for $d=.31$ and $\alpha=.01$. The level of significance seems appropriate because there are multiple outcomes and an adjustment is necessary. Sample size was calculated based on the design: we used a 3 x 2 x 2 factorial design (time: pre-assessment vs. post-assessment vs. 3-month follow-up; condition: training group vs. control group; initial general self-efficacy: low self-efficacy vs. high self-efficacy) with time as a repeated measurement. Power was set as $(1-\beta)=.80$, thus, a sample size of 210 is necessary and sufficient (Bortz \& Döring, 1995). We asked a total of 300 students and their parents for consent to participate as a precaution against the high dropout rates reported in previous studies (e. g., 30\%; Gillham et al., 1995).

\footnotetext{
${ }^{1}$ We used therapy group instead of class as a test; however, the results were not affected.
} 
All analyses were carried out using the software package "SPSS for Windows 11". We calculated mixed models with repeated measures. We used the pre-assessment values of the dependent variables and the values of BJL and HASSUP as covariates. Pairwise comparisons were done with Bonferroni tests following significant interactions in ANCOVAS. We used the subcommand EMMEANS, which ensures that SPSS uses identical degrees of freedom for both the ANCOVA and the respective a posteriori tests. Significance levels of the a posteriori tests were automatically adjusted with the Bonferroni correction. Effect sizes were calculated following Hedges's $g=$ (mean of the one group - mean of the other group) devided by pooled standard deviation of both groups (Cohen, 1988). Effect sizes are displayed as positive values when in line with our hypotheses, and as negative values when contradicting them.

In order to test the model of mediation, we followed Baron and Kenny (1986). Thus, three conditions must hold in a series of regression models: First, the independent variable (condition) must affect the mediator (dysfunctional thoughts, network size or frequency) in a regression of the mediator on the independent variable. Second, the independent variable must be shown to affect the dependent variable (depressive symptoms) in a regression equation of the dependent on the independent variable. Last, in a regression of the dependent variable on both the independent variable and on the mediator, the mediator must affect the dependent variable and the effect of the independent variable on the dependent variable must be less in the third equation than in the second. If the effect of the condition is entirely eliminated, complete mediation holds. If the effect of the independent variable is reduced but not entirely eliminated, partial mediation holds. We expect our prevention program LISA to cause changes in the mediators and in the depressive symptoms. Therefore, we used the preassessment score of the mediators as an independent variable in the first regression model, and the pre-assessment score of depressive symptoms as an independent variable in the 
second and third regression model. The model of mediation was tested for each mediator and for students with high vs. low self-efficacy separately.

We inspected the questionnaires for missing values after each assessment. Nevertheless, we could not prevent students from skipping some of the items. Thus, sample size is reduced in some analyses compared to the actual number of participating students. We compared students skipping questions with those who did not. There were no noticeable differences.

Results

For initial general self-efficacy a significant difference was found for depressive symptoms, $F(1,278)=47.93, p=.000$ (low self-efficacy: $\mathrm{M}=18.72$; high self-efficacy: $\mathrm{M}=$ 12.04) and dysfunctional thoughts, $F(1,204)=11.53, p=.001$ (low self-efficacy: $\mathrm{M}=52.97$; high self-efficacy: $M=46.18)$. No significant differences were found for sex, $F(1,278)=$ $.05, p=.830$, age $F(1,278)=1.05, p=.307$, network size, $F(1,204)=1.40, p=.239$ or frequency, $F(1,204)=.06, p=.800$ at pre-assessment. For experimental condition no significant differences were found for depressive symptoms, $F(1,278)=1.67, p=.197$, or sex, $F(1,278)=2.57, p=.110$, but for age: $F(1,278)=14.45, p=.000$ (training group: $\mathrm{M}=$ 13.78; control group: $M=14.12)^{2}$. No significant differences for an initial general selfefficacy $\mathrm{x}$ experimental condition interaction were found for depressive symptoms, $F(1,278)$ $=.11, p=.738$, sex $F(1,278)=2.08, p=.151$, or age, $F(1,278)=2.26, p=.134$. For descriptive statistics of the depressive symptoms, dysfunctional thoughts, and social network see Table 1. The correlations between all scales are presented in Table 2.

\section{Distal Objective}

We found significant effects concerning the depressive symptoms for the main effect of condition, $F(1,156)=6.04, p<.05$, as well as for the time $\mathrm{x}$ condition $\mathrm{x}$ self-efficacy interaction, $F(1,156)=7.17, p<.01$. Comparing pairwise, level of depression (CES-D 
score) of adolescents with low self-efficacy within the control group were increasing significantly between post-assessment $(n=30$, mean $=13.93, \mathrm{SD}=7.44)$ and 3 -month follow-up $(\mathrm{n}=30$, mean $=17.17, \mathrm{SD}=7.65), F(1,156)=5.91, p<.05, \mathrm{~g}=.43(95 \% \mathrm{CI}$ for effect size $=-0.09-0.95)$. Furthermore, in the 3-month follow-up, level of depression of adolescents with low self-efficacy were significantly lower in the training group $(n=42$, mean $=12.02, \mathrm{SD}=6.18)$ than in the control group $(\mathrm{n}=30$, mean $=17.17, \mathrm{SD}=7.65), F(1$, $156)=10.21, p<.01, \mathrm{~g}=.75(95 \% \mathrm{CI}$ for effect size $=0.26-1.24)$. We found no additional significant results for pairwise comparisons.

\section{Proximal Objectives}

Concerning dysfunctional automatic thoughts as measured by the ATQ; we found a significant interaction for time x condition, $\underline{F}(1,138)=5.12, p<.05$. None of the pairwise comparisons were significant.

For network size we found a significant interaction effect for time $\mathrm{x}$ condition $F(1,142)=$ 4.93, $p<.05$. Compared pairwise, network size of adolescents within the training group was increasing significantly between post-assessment $(\mathrm{n}=95$, mean $=2.27, \mathrm{SD}=1.36)$ and 3 month follow-up $(\mathrm{n}=95$, mean $=2.57, \mathrm{SD}=1.80), F(1,142)=4.10, p<.05, \mathrm{~g}=.19(95 \%$ CI for effect size $=-0.10-0.48$ ). Furthermore, network size of adolescents was significantly larger in the training group $(\mathrm{n}=95$, mean $=2.57, \mathrm{SD}=1.80)$ than in the control group $(\mathrm{n}=$ 64 , mean $=2.39, \mathrm{SD}=1.03)$ in the 3-month follow-up, $F(6.04)=1,142, p<.05, \mathrm{~g}=.13$ $(95 \%$ CI for effect size $=-0.19-0.45)$. No other significant pairwise comparisons were found.

The frequency of use of social network showed a significant main effect for time $F(1$, $130)=4.91, p<.05$, as well as for the time $\mathrm{x}$ condition interaction, $F(1,130)=6.73, p<.05$ and the time $\mathrm{x}$ condition $\mathrm{x}$ self-efficacy interaction, $F(1,130)=6.08, p<.05$.

\footnotetext{
${ }^{2}$ Due to this difference, we also calculated all ANCOVAs with age as a covariate. No interactions of age and
} 
Compared pairwise, frequency scores within the low self-efficacy control group were decreasing significantly between post-assessment $(\mathrm{n}=28$, mean $=3.45, \mathrm{SD}=.99)$ and 3month follow-up $(\mathrm{n}=28$, mean $=3.09, \mathrm{SD}=.97), F(1,130)=5.03, p<.05, \mathrm{~g}=.37(95 \% \mathrm{CI}$ for effect size $=-0.17-0.91)$. The frequency scores of adolescents within the high selfefficacy control group were increasing significantly between post-assessment $(n=33$, mean $=$ $3.15, \mathrm{SD}=.76)$ and 3 -month follow-up $(\mathrm{n}=33$, mean $=3.56, \mathrm{SD}=.93), F(1,130)=5.92, p$ $<.05, \mathrm{~g}=-.49(95 \% \mathrm{CI}$ for effect size $=-0.99-0.01)$. No further significant pairwise comparisons could be found.

\section{Testing mediation}

We hypothesized that the prevention program influences dysfunctional thoughts, network size, and frequency of the use of network, which, in turn, influences depressive symptoms. We found no influence of LISA on dysfunctional thoughts, thus, thoughts were not analysed as a potential mediator.

Table 3 shows the results of the mediation testing: network size and frequency of use do not mediate the prevention program and changes in depressive symptoms between preassessment and 3-month follow-up.

\section{Discussion}

In line with our hypothesis, the primary prevention program LISA was effective. As expected, participants of the prevention program LISA remained on a low level of depressive symptoms and had larger social network sizes, while the control group showed increasing amounts of depressive symptoms and a reduced use of social network, especially in the low self-efficacy group. Regarding the 3-month follow-up, participants in the training group showed significantly greater network sizes compared to post-assessment and compared to the 
control group. However, the effect sizes for the changes in social network sizes do not differ significantly from zero.

Participants low on self-efficacy benefited most from LISA and showed significantly less depressive symptoms than comparable controls in the 3-month follow-up. This supports the positive effects of LISA. Interestingly, students of the control group high on self-efficacy increased the frequency of their social network in the run of the study, while participants of the prevention program did not. Again, effect sizes are not significant.

Unexpectedly,(1) we found only non-significant effect sizes for the effects of LISA on social network (size and frequency); (2) changes in the social network did not mediate the relationship between program and changes in depressive symptoms; (3) LISA is more effective in students low in self-efficacy than in students high in self-efficacy and (4) we could not show an impact of our program on dysfunctional thoughts.

Non-significant effect sizes for social network might be due to slow changes in adolescents' social structure. It is possible that LISA caused an increase in appropriate social behaviors even if we were unable to register it in the 3-month follow-up. Processes of change in social structures might be too slow to show effects after a 3-month period. If we accepted this explanation, we would not expect a mediating role of social networks.

Social support, based on social competence, is a protective factor against the development of a depression due to critical life events and daily hassles,. However, it might also be possible that increased social competence might by itself lead to more effective handling of daily hassles. It might support appropriate social interactions with parents, teachers, and peers and thus reduce the stressful impact of daily hassles. However, this is speculative, because we did not measure stress handling.

covariate. 
Contrary to our hypothesis, we found that LISA affects primarily students low in selfefficacy. However, control group students low in self-efficacy showed now increases in depressive symptoms until 3-month follow-up, and the same was true for the control group students high in self-efficacy. Thus, there was no increase in symptoms that the training could have affected.

Despite statistical significance, effect sizes for social network variables do not differ significantly from zero. Students of the control group who scored high on self-efficacy made increasing use of existing social networks. Students of the training group extended their social networks irrespective of their self-efficacy values. Possibly, low self-efficacy adolescents in the control group did not actively search for social support in difficult situations because they are less frequently involved in social situations, see themselves as not able to cope well with social interactions, and hence tend to avoid them. The opposite might be true for high self-efficacy students who perceive themselves as competent in social interactions and who are better able to accept and use help (Klauer, 2000). The prevention program LISA incorporates several components that help establish more functional interpretations of and more appropriate reactions to social situations. It enables students to become sensible to and cope well with interactions. In our opinion, this also helps students to ask not just anybody for help but to decide on the most appropriate person and, consequently, follow this person's advice. Thus, it could be possible that adolescents in the training group did not increase the use of the available network but enlarged their social networks instead. Our results show that students low on self-efficacy benefited more from the prevention program than students high on self-efficacy. This contradicts with our hypothesis, expecting participants high on self-efficacy to be more motivated to transfer trained contents into real life and to show more changes in outcome variables. Although self-efficacy on the one hand and network size and frequency on the other hand are independent variables at pre- 
assessment, we speculate that students high on self-efficacy do actively look for support in critical situations, whereas students low on self-efficacy are less frequently involved in social situations, perceive themselves as unable to cope well with social interactions, and hence tend to avoid them. The prevention program incorporates many behavioral interventions, e.g. role plays, in which all participants got involved. It is seems plausible that subjects low on selfefficacy benefited more from the training and the group setting because they are used to similar settings and have a different behavioral base rate.

Contrary to our hypotheses, none of the pairwise comparisons was significant for dysfunctional thoughts. This finding, however, is in line with results found in preceding prevention studies. For example, Seligman and colleagues (Gillham et al., 1995) did not find changes in adolescents' attributional styles at until the 12-month follow-up in the training group. Delay of significant effects in cognitive variables might be due to the fact that students have to practice and consistently implement the newly learned techniques in their daily lives in order to develop more functional in automatic thoughts.

Our prevention program differs from other less successful universal programs in the use of same sex groups and in the fact that many groups were smaller than those used in other studies (Clarke et al., 1993; Spence, Sheffield, \& Donovan, 2003). Furthermore, each group was trained by two trainers. This high trainer to student ratio might be one important reason for the success of our program. Another factor might be the separation of both genders in separate groups.

There are several limitations to this study: A major limitation with regard to our data is the sole use of students' self-reports in questionnaires. We did not compare these data with reports of parents, teachers, or peers, and neither did we use clinical diagnoses or behavioral observation. Using self-reports might be problematic in the training groups, as students could 
have inferred desired answers from the content of the training. However, the positive effect of LISA is not based on changes in the training group, but on changes in the control group.

Furthermore, previous studies (for an overview see Kazdin, 1994) have shown that there is a moderate correlation between self-reports and reports from others and that adolescents are a reliable source of information. This is particularly true for internalizing disorders such as depression. In addition, adolescents with elevated self-reported depressive symptoms develop more depression and other mental disorders and face more difficulties in psychosocial functioning than students without depressive symptoms (Gotlib, Lewinsohn, \& Seeley, 1995). Nevertheless, in this study, conclusions can only be drawn with regard to depressive symptoms, not with regard to the prevention of depressive disorders. Multiple self-reports might have increased the reliability of our results. Another limitation stems from the influence of drop-outs on our results. By excluding drop-outs from the analyses, we might receive systematically biased results in favor of our program. In our study, 15 boys and nine girls quit the training group and were subsequently excluded from the analyses. However, a possible exaggeration of the training effect is small because the reason for the drop-out occurred before the training started. In addition, the number of drop-outs was low. The severity of depressive symptoms was similar in drop-outs and remaining participants. Another limitation is that the students were not blind to their condition and might have reported positive effects of the prevention program due to demand characteristics. However, we did not find a positive effect for dysfunctional thoughts, although students of the training group knew that changing of dysfunctional thoughts is an aim of the program. Furthermore, there are positive effects of the prevention program on depressive symptoms although students were blind to this major goal. Our control groups received no treatment at all, so no statements can me made regarding possible placebo effects of the prevention program. In prevention studies, long-term effects after three months need to be replicated and ascertained. 
In our study, adolescents high on self-efficacy show less depressive symptoms than those low on self-efficacy. We therefore cannot entirely exclude the alternative explanation that differential effects of LISA on youths with high vs. low self-efficacy values are really due to symptom characteristics. The two interpretations in question are difficult to separate because people low in self-efficacy are more likely to perceive themselves as incompetent and deficient, to overestimate failure, and thus to develop behavioral deficits and depressive symptoms (Bandura, 1977). However, several arguments exist against this alternative explanation. First, pre-assessment scores of depressive symptoms were used as a covariate in the analysis of depressive symptoms, thus controlling for the influence of pre-assessment symptoms. Comparing students high vs. low on depressive symptoms, we found that both groups benefited from the prevention program, however, the pattern of results is different. For example, no influence was found with regard to frequency of use of social networks. ${ }^{3}$

Second, age differences between the groups point to a randomization error. Very likely, this is due to the small number of units (12 classes). Thus, there is a good chance that the conditions are not well matched.

As a final limitation, we did not measure social competence as socially appropriate behaviors. Measures such as the "Interpersonal Problem-Solving Questionnaire” (IPSQ; Rudolph, Hammen, \& Burge, 1994) could be used.

\section{Conclusion}

Despite these limitations, we conclude that the school-based prevention program LISA had favorable effects in a large sample of German adolescents. This study indicates that selfefficacy moderates the effects of prevention programs. Although positive effects on selfreported depressive symptoms were restricted to adolescents with low general self-efficacy, we nevertheless recommend administering LISA to all students. First, universal programs

\footnotetext{
${ }^{3}$ These results have been omitted due to lack of space. More detailed report can be obtained by contacting the
} 
prevent stigmatization of the individual participant. Second, we found positive effects of the program on the network size of all students. Third, we know little about the influence of students without depressive symptoms and higher competences in certain areas, e.g., in establishing contact; however, it is likely that they provide mastery models and exert a positive influence (Lowry-Webster, Barrett, \& Dadds, 2001). More research is needed on self-efficacy as a mediator in prevention programs, and on peers as mastery models. Group size and separation of sexes are possible moderators; their influence should be tested in future studies. 


\section{Acknowledgements}

We would like to thank the adolescents, parents, and teachers involved in the project and express our gratitude to the local education agency of Tuebingen for making this project possible. Furthermore, we are grateful to three anonymous reviewers for their extensive and valuable comments on an earlier version of this article.

The project was supported within the DFG graduate program grant, "Lifestyles, Social Inequalities and Health Promotion” by grants for Patrick Pössel and Andrea B. Horn. 
Correspondence to

Patrick Pössel, Ph. D.

Department of Clinical and Physiological Psychology

Eberhard-Karls-University

Christophstr. 2

72072 Tuebingen

Germany

Phone: $+49-7071-2977181$

Fax: +49-7071 - 360502

E-mail: patrick.poessel@uni-tuebingen.de 


\section{References}

Abramson, L. Y., Alloy, L. B. \& Metalsky, G. I. (1989). Hopelessness depression: a theorybased subtype of depression. Psychological Bulletin, 96, $358-372$.

Bandura, A. (1977). Self-efficacy: Toward a unifying theory of behavioural change. Psychological Review, 84, 191 - 215.

Baron, R. M., \& Kenny, D. A. (1986). The moderator-mediator variable distinction in social psychological research: Conceptual strategic, and statistical considerations. Journal of Personality and Social Psychology, 51, $1173-1182$.

Barrera, M. Jr., \& Garrison-Jones, C. (1992). Family and peer social support as specific correlates of adolescent depressive symptoms. Journal of Abnormal Child Psychology, $20,1-16$.

Beck, A. T., Rush, A. J., Shaw, B. F., \& Emery, G. (1979). Cognitive Therapy of Depression. New York: The Guilford Press.

Bennett, D. S. \& Bates, J. E. (1995). Prospective models of depressive symptoms in early adolescence. Attributional style, stress, and support. Journal of Early Adolescence, 15, $299-315$.

Birmaher, B., Ryan, N. D., Williamson, D. E., Brent, D. A., Kaufman, J., Dahl, R. E., Perel, J., \& Nelson, B. (1996). Childhood and adolescent depression: A review of the past 10 years. Part I: Journal of the American Academy of Child and Adolescent Psychiatry, 35, $1427-1439$.

Bliesener, T. (1991). Soziale Unterstützung im Jugendalter: Konstruktion und Validierung eines Instruments zu ihrer Erfassung. Psychologische Beiträge, 33, 434 - 462.

Bortz, J. \& Döring, N. (1995). Forschungsmethoden und Evaluation. Berlin: Springer. 
Brent, D. A., Birmaher, B., Kolko, D., Baugher, M., \& Bridge, J. (2001). Subsyndromal depression in adolescents after a brief psychotherapy trial: course and outcome. Journal of Affective Disorders, 63, 51 - 58.

Brown, C. H., \& Liao, J. (1999). Principles for designing randomized preventive trails in mental health: An emerging developmental epidemiology paradigm. American Journal of Community Psychology, 27, $677-714$.

Clarke, G. N., Hawkins, W., Murphy, M., \& Sheeber, L. (1993). School-based primary prevention of depressive symptomatology in adolescents: Findings from two studies. Journal of Adolescent Research, 8, 183 - 204.

Clarke, G. N., Hornbrook, M., Lynch, F., Polen, M., Gale, J., Beardslee, W., O’Connor, E. \& Seeley, J. (2001). A randomized trial of a group cognitive intervention for preventing depression in adolescent offspring of depressed parents. Archives of General Psychiatry, $58,1127-1134$

Clarke, G. N., Rohde, P., Lewinsohn, P. M., Hops, H., \& Seeley, J. R. (1999). Cognitivebehavioral treatment of adolescent depression: Efficacy of acute group treatment and booster sessions. Journal of the American Academy of Child and Adolescent Psychiatry, $38,272-279$.

Cohen, J. (1988). Statistical Power Analysis for the Behavioral Sciences. New York: Erlbaum.

Coie, J. D., Watt, N. F., West, S. G., Hawkins, J. D., Asarnow, J. R., Markman, H. J., Ramey, S. L., Shure, M. B., \& Long, B. (1993). The science of prevention: a conceptual framework and some directions for a national research programme. American Psychologist, 48, 1013 - 1022. 
Colquitt, J. A., LePine, J. A., \& Noe, R. A. (2000). Toward an integrative theory of training motivation: A meta-analytic path analysis of 20 years of research. Journal of Applied Psychology, 85, 678-707.

Compas, B. E., Connor, J., \& Wadsworth, M. (1997). Prevention of depression. In: R. P. Weissberg, T. P. Gullotta, R. L. Hampton, B. A. Ryan, \& G. R. Adams (Eds.), Healthy Children 2010: Enhancing Children's Wellness (pp . 129 - 174). London: Sage Publications.

Compas, B. E., Ey, S., \& Grant, K. E. (1993). Taxonomy, assessment, and diagnosis of depression during adolescence. Psychological Bulletin, 114, 323 - 344.

Dodge, K. A. (1993). Social-cognitive mechanisms in the development of conduct disorder and depression. Annual Review of Psychology, 44, 559 - 584.

Dumont, H., Hébert, M., \& Lavoie, F. (1999). La contribution des caractéristiques individuelles aux apprentissages des enfants du primaire participant à un atelier de pévention des abus. Revue Canadienne de Santé Mentale Communautaire, 18, 39-56.

Dumont, M. \& Provost, M. A. (1999). Resilience in adolescents: protective role of social support, coping strategies, self-esteem and social acivities on experience of stress and depression. Journal of Youth and Adolescence, 28, 343 - 363.

Durlak, J. A., \& Wells, A. M. (1997). Primary prevention mental health programmes for children and adolescents: A meta-analytic review. American Journal of Community Psychology, 25, $115-152$.

Essau, C. A., Karpinski, N. A., Petermann, F., \& Conradt, J. (1998). Häufigkeit, Komorbidität und psychosoziale Beeinträchtigung von Depressiven Störungen bei Jugendlichen: Ergebnisse der Bremer Jugendstudie. Zeitschrift für Klinische Psychologie, Psychiatrie und Psychotherapie, 46, 316 - 329. 
Garber J., Weiss, B, \& Shanley, N. (1993). Cognitions, depressive symptoms, and development in adolescents. Journal of Abnormal Psychology, 102, 47 - 57.

Gillham, J. E., Reivich, K. J., Jaycox, L. H., \& Seligman, M. E. P. (1995). Prevention of depressive symptoms in schoolchildren: Two-year follow-up. Psychological Science, 6, $343-351$.

Goldstein, H. (1995). Multilevel statistical models. London: Arnold.

Gotlib, I. H., Lewinsohn, P. M., \& Seeley, J. R. (1995). Symptoms versus a diagnosis of depression: Differences in psychosocial functioning. Journal of Consulting and Clinical Psychology, 63, $90-100$.

Harrington, R., Fudge, H., Rutter, M., Pickles, A. \& Hill, J. (1990). Adult outcomes of childhood and adolescent depression, I: psychiatric status. Archives of General Psychiatry, 47, $465-473$.

Hollon, S. D., \& Kendall, P. C. (1980). Cognitive self-statements in depression: Development of an Automatic Thoughts Questionnaire. Cognitive Therapy and Research, 4, 383 - 397.

Hopkins, K. D. (1982). The unit of analysis: Group means versus individual observations. American Educational Research Journal, 19, 5 - 18.

Hurrelmann, K., \& Settertobulte, W. (2000). Prävention und Gesundheitsförderung. In F. Petermann (Eds.), Lehrbuch der Klinischen Kinderpsychologie und-psychotherapie (pp. 131 - 148). Göttingen: Hogrefe.

Jerusalem, M. \& Schwarzer, R. (1986). "Selbstwirksamkeit". WIRK. In R. Schwarzer (Eds.), Skalen zur Befindlichkeit und Persönlichkeit (pp. 15 - 28). Berlin: Freie Universität, Institut für Psychologie.

Kazdin A.E. (1994). Informant variability in the assessment of childhood depression. In W. M. Reynolds H. F. Johnston (Eds), Handbook of depression in children and adolescents (pp 249 - 271). New York: Plenum Press. 
Kröger, Ch., Kutza, R., Walden, K. \& Reese, A. (1998). Implementation eines Lebenskompetenzprogrammes für fünfte Klassen an Hauptschulen und Gymnasien. Kindheit und Entwicklung, 7, $231-238$.

Klauer, T. (2000). Das Selbst und die Nutzung sozialer Ressourcen. In W. Greve (Eds.), Psychologie des Selbst (pp. 146-166). Weinheim: Psychologie Verlags Union.

Lewinsohn, P. M., Solomon, A., Seeley, J. R., \& Zeiss, A. (2000). Clinical implications of “subthreshold" depressive symptoms. Journal of Abnormal Psychology, 109, 345 - 351.

Lightsey, O. R. (1994). Positive automatic cognitions as moderators of the negative life event $^{\wedge}$ dysphoria relationship. Cognitive Therapy and Research, 18, $353-365$.

Llopis, E. J. (2002). What makes the ounce of prevention effective? A meta-analysis of mental health promotion and mental disorder prevention programmes. Nijmegen: Quickprint.

Lowry-Webster, H. M., Barrett, P. M. \& Dadds, M. R. (2001). A universal prevention trial of anxiety and depressive symptomatology in childhood: Preliminary data from an Australian study. Behaviour Change, 18, 36 - 50.

Moreau, D., Mufson, L., Weissman, M. M. \& Kleman, G. L. (1991). Interpersonal psychotherapy for adolescent depression: Description of modification and preliminary application. Journal of the American Academy of Child and Adolescent Psychiatry, 30, $642-651$.

Nolen-Hoecksema, S., \& Girgus, J. S. (1994). The emergence of gender differences in depression during adolescence. Psychological Bulletin, 115, 424 - 443.

Pössel, P., Horn, A. B. \& Hautzinger M. (2003). Erste Ergebnisse eines Programmes zur schulbasierte Prävention von depressiven Symptomen bei Jugendlichen. Zeitschrift für Gesundheitspsychologie, 11, 10-20.

Pössel, P., Horn, A. B., Seemann, S. \& Hautzinger, M. (2004). Trainingsprogramm zur Prävention von Depressionen bei Jugendlichen. LARS\&LISA: Lust An Realistischer Sicht \& Leichtigkeit Im Sozialen Alltag. Hogrefe: Göttingen. 
Quast, H. H., Jerusalem, M., \& Faulhaber, J. (1986). Daily hassles and daily uplifts. In R. Schwarzer (Eds.), Skalen zur Befindlichkeit und Persönlichkeit (Forschungsbericht 5). Berlin: Freie Universitaet, Institut für Psychologie.

Radloff, L. S. (1977). The CES-D: A self-report symptom scale to detect depression in the general population. Applied Psychological Measurement, 3, 385 - 401.

Roberts, R. E., Andrews, J. A., Lewinsohn, P. M., \& Hops, H. (1990). Assessment of depression in adolescents using the Center for Epidemiologic Studies Depression Scale. Psychological Assessment, 2, $122-128$.

Rudolph, K. D., Hammen, C. \& Burge, D. (1994). Interpersonal functioning and depressive symptoms in childhood: Addressing the issues of specificity and comorbidity. Journal of Abnormal Child Psychology, 22, 355 - 371.

Schwarzer, R. (1994). Optimistische Kompetenzerwartung: Zur Erfassung einer personellen Bewältigungsressource. Diagnostica, 40, 105-123.

Sheeber, L., Hops, H. \& Davis, B. (2001). Family processes in adolescent depression. Child and Family Psychology Review, 4, 19 - 35.

Shochet, I. M., Dadds, M. R., Holland, D., Whitefield, K., Harnett, P. H., \& Osgarby, S. M. (2001). The efficacy of a universal school-based programme to prevent adolescent depression. Journal of Clinical Child Psychology, 30, 303 - 315.

Spence, S. H., Sheffield, J. K. \& Donovan, C. L. (2003). Preventing adolescent depression: An evaluation of the Problem Solving for Life Program. Journal of Consulting and Clinical Psychology, 71, $3-13$.

Vernberg, E. M. (1990). Psychological adjustment and experiences with peers during early adolescene: Reciprocal, incidental, or unidirectional relationships? Journal of Abnormal Child Psychology, 18, 187 - 198. 
Weissman, M. M., Wolk, S., Goldstein, R. B., Moreau, D., Adams, P., Greenwald, S., Klier, C. M., Ryan, N. D., Dahl, R. E., \& Wickramaratne, P. (1999). Depressed adolescents grown up. JAMA, 281, $1707-1713$. 
Table 1

Descriptive statistics of the CES-D, ATQ, and FESU, separated according to time, group, and general self-efficacy

\begin{tabular}{|c|c|c|c|c|c|c|}
\hline & $\mathrm{T} 1$ & $\mathrm{~T} 2$ & T3 & $\mathrm{T} 1$ & $\mathrm{~T} 2$ & T3 \\
\hline & $\begin{array}{c}\mathrm{M} / \mathrm{SD} \\
(\mathrm{n}=53)\end{array}$ & $\begin{array}{c}\mathrm{M} / \mathrm{SD} \\
(\mathrm{n}=50)\end{array}$ & $\begin{array}{c}\mathrm{M} / \mathrm{SD} \\
(\mathrm{n}=52)\end{array}$ & $\begin{array}{c}\mathrm{M} / \mathrm{SD} \\
(\mathrm{n}=43)\end{array}$ & $\begin{array}{c}\mathrm{M} / \mathrm{SD} \\
(\mathrm{n}=39)\end{array}$ & $\begin{array}{c}\mathrm{M} / \mathrm{SD} \\
(\mathrm{n}=37)\end{array}$ \\
\hline \multicolumn{7}{|c|}{ low general self-efficacy } \\
\hline & \multicolumn{3}{|c|}{ training group } & \multicolumn{3}{|c|}{ control group } \\
\hline CES-D & $15.64 / 5.45$ & $14.08 / 6.67$ & $12.68 / 6.40$ & $14.71 / 5.54$ & $13.60 / 7.17$ & $16.27 / 8.21$ \\
\hline ATQ & $51.20 / 13.86$ & $48.19 / 17.71$ & $41.60 / 11.43$ & $54.73 / 16.88$ & $49.08 / 19.67$ & $47.16 / 18.18$ \\
\hline FESU-N & $2.03 / 1.14$ & $2.03 / 1.27$ & $2.31 / 1.28$ & $2.36 / .99$ & $2.61 / 1.39$ & $2.28 / .92$ \\
\hline FESU-F & $3.27 / .85$ & $3.37 / 1.14$ & $3.23 / .89$ & $3.47 / .91$ & $3.38 / .90$ & $3.29 / .99$ \\
\hline GSE & $22.70 / 3.62$ & $25.48 / 5.18$ & $26.27 / 6.17$ & $23.04 / 3.99$ & $26.81 / 4.81$ & $25.78 / 4.12$ \\
\hline
\end{tabular}


Table 1 (continued)

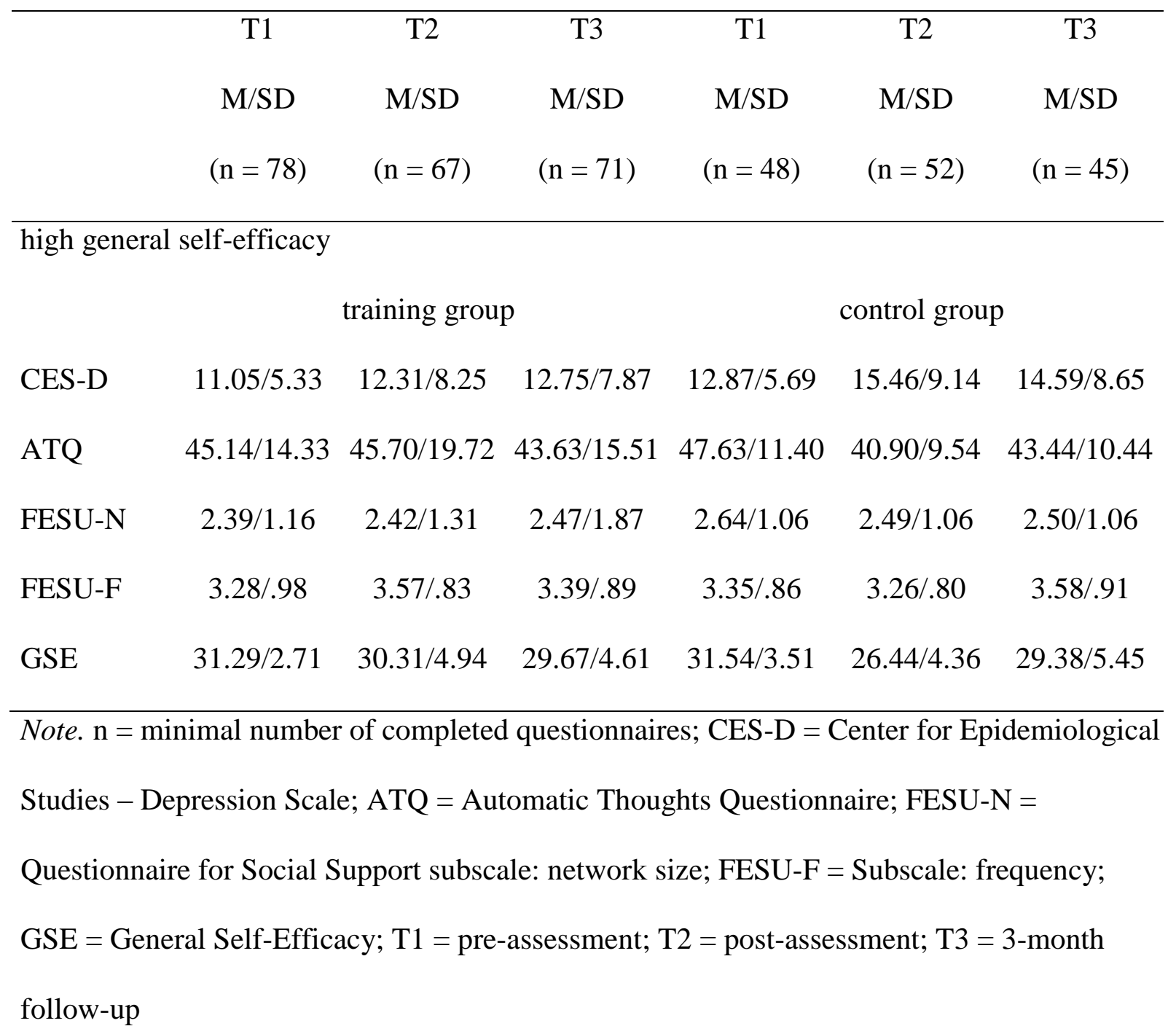


Table 2

Correlations between the scales of the CES-D, ATQ, FESU, GSE, BJL, and HASSUP $(N=231)$

\begin{tabular}{|c|c|c|c|c|c|c|c|}
\hline & CES-D & ATQ & FESU-N & FESU-F & GSE & BJL & HASSUP-DH \\
\hline FESU-N & $.13 *$ & .07 & & & & & \\
\hline FESU-F & .00 & -.01 & .01 & & & & \\
\hline GSE & $-.33 * *$ & $-.29 * *$ & $.14 *$ & -.06 & & & \\
\hline BJL & $.13 *$ & $.19 * *$ & $.22 * *$ & $.14 *$ & -.02 & & \\
\hline HASSUP-DH & $.35 * *$ & $.46 * *$ & .11 & $.13 *$ & $-.14 *$ & $.28 * *$ & \\
\hline HASSUP-DU & $-.30 * *$ & $-.33 * *$ & $.16 *$ & -.08 & $.31 * *$ & -.02 & $-.46 * *$ \\
\hline
\end{tabular}

Note. CES-D = Center for Epidemiological Studies - Depression Scale; ATQ = Automatic Thoughts Questionnaire; FESU-N = Questionnaire for Social Support subscale: network size; FESU-F = Subscale: frequency; GSE = General Self-Efficacy; BJL = Bremen Youth's Event List;

HASSUP-DH = Daily Hassles and Daily Uplifts Questionnaire subscale: daily hassles; HASSUP-DU = Daily Hassles and Daily Uplifts

Questionnaire subscale: daily uplifts 
Table 3

Condition, social network size, and frequency of use of social network predicting changes in depressive symptoms by students low $(n=75)$ and high in self-efficacy $(n=110)$

\begin{tabular}{|c|c|c|c|c|c|}
\hline order of entry of set & predictors in set & $\mathrm{F}$ for set & $\mathrm{t}$ for set predictors & df & $\mathrm{pr}$ \\
\hline \multicolumn{6}{|c|}{ network size, low self-efficacy } \\
\hline \multirow[t]{3}{*}{1.} & & $3.26 *$ & & 2,83 & \\
\hline & FESU-Nt1 & & $2.53 *$ & & .27 \\
\hline & condition & & -.73 & & -.08 \\
\hline \multirow[t]{3}{*}{2.} & & $4.95 * *$ & & 2,90 & \\
\hline & CES-Dt1 & & $2.03 *$ & & .21 \\
\hline & Condition & & $2.51 *$ & & .26 \\
\hline \multirow[t]{4}{*}{3.} & & $3.10 *$ & & 3,88 & \\
\hline & CES-Dt1 & & $1.99 *$ & & .21 \\
\hline & condition & & $2.41 *$ & & .25 \\
\hline & FESU-Nt3 & & -.43 & & -.05 \\
\hline
\end{tabular}


Table 3 (continued)

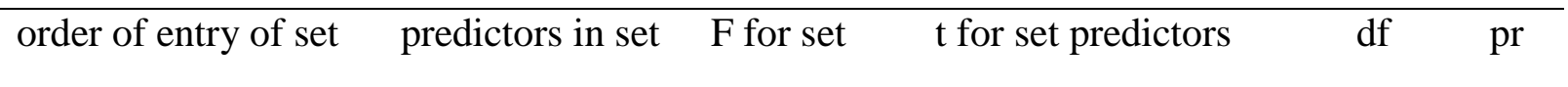

high self-efficacy

1.

$16.05 * *$

2, 107

FESU-Nt1

5.66*

.48

condition

$-.44$

$-.04$

2.

$10.27 * *$

2, 116

CES-Dt1

$4.35^{* *}$

Condition

.43

.04

3.

$7.72 * *$

3, 115

CES-Dt1

$3.73 *$

.33

condition

.51

.05

FESU-Nt3

1.55

.14 
Table 3 (continued)

order of entry of set $\quad$ predictors in set $\quad \mathrm{F}$ for set $\quad \mathrm{t}$ for set predictors $\quad \mathrm{df} \quad \mathrm{pr}$

frequency of use of network, low self-efficacy

1.

$3.17 *$

2,72

FESU-Ft1

$2.41 *$

.27

condition

$-.84$

$-.10$

2.

$4.95 * *$

2,90

CES-Dt1

$2.03 *$

.21

condition

$2.51 *$

.26

3.

$4.24 * *$

3,86

CES-Dt1

1.59

.17

condition

$2.39 *$

.25

FESU-Ft3

1.91

.20 
Table 3 (continued)

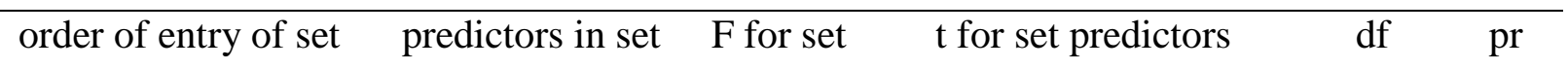

high self-efficacy

1.

$10.44 * *$

2, 103

FESU-Ft1

$4.45 * *$

condition

.66

.07

2.

$10.27 * *$

2, 116

CES-Dt1

$4.35^{* *}$

.37

condition

.43

.04

3.

$7.13 * *$

3, 114

CES-Dt1

$4.04 * *$

condition

FESU-Ft3

Note. pr $=$ partial correlation for within-set predictors; FESU-Nt1 = network size at preassessment; FESU-Nt3 = network size at 3-month follow-up; FESU-Ft1 = frequency of use of network at pre-assessment; FESU-Ft1 = frequency of use of network at 3-month follow-up; CES-Dt1 $=$ depressive symptoms at pre-assessment; condition $=$ training group vs. control group $* *=\mathrm{p} \leq .05 ; * *=\mathrm{p} \leq .01$ 
Figure 1. Flow chart describing sample size and drop out of students within the study. 


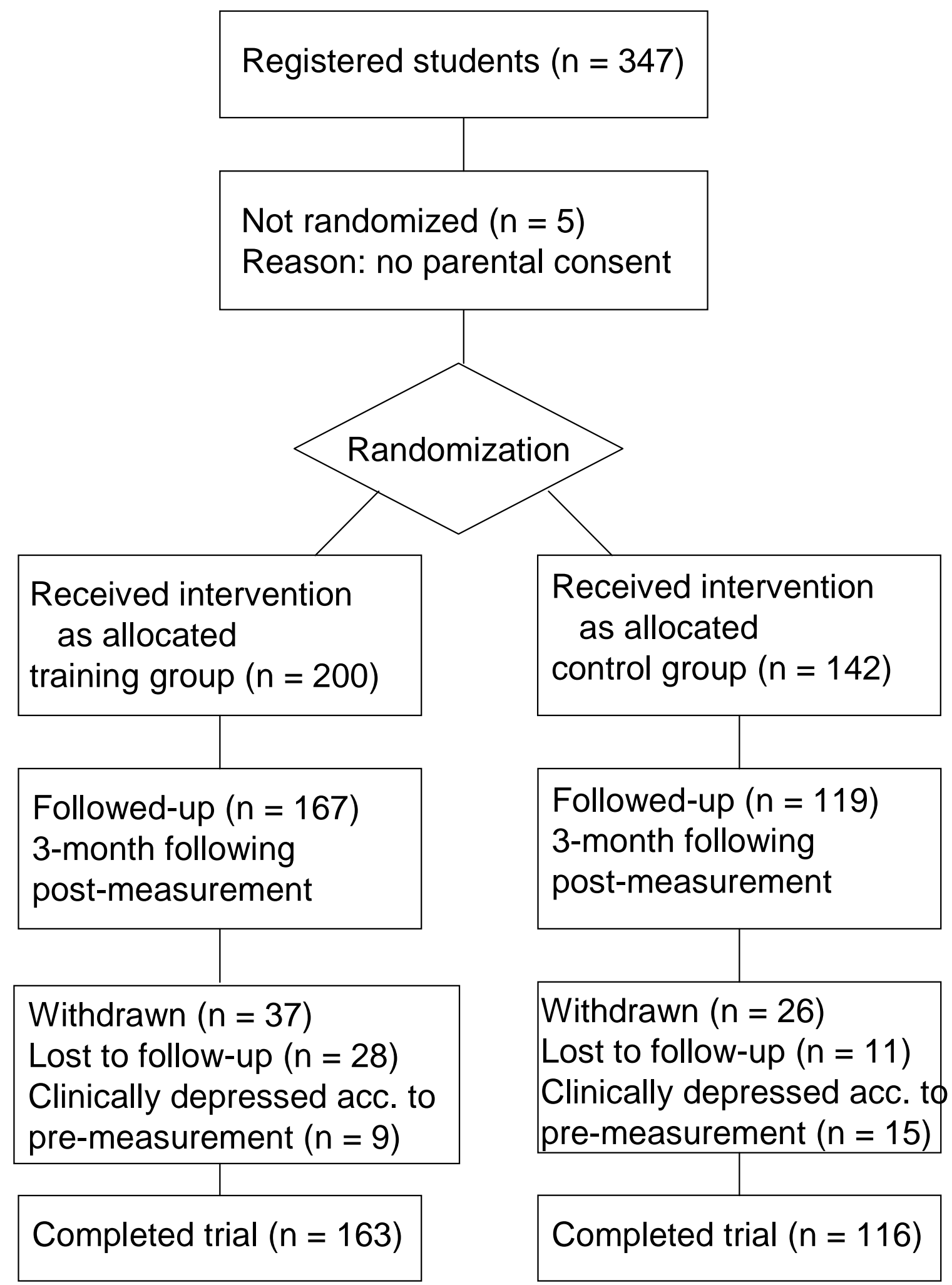

